\title{
Pengaruh Fundamental Ekonomi dan Kinerja Keuangan Terhadap Kredit Bermasalah Pada Bank Syariah Di Indonesia
}

\author{
Soeharjoto Soekapdjo \\ Universitas Trisakti \\ soeharjoto@trisakti.ac.id \\ Debbie Aryani Tribudhi \\ Universitas Trisakti \\ debbie.aryani@trisakti.ac.id \\ Lucky Nugroho \\ Universitas Mercu Buana \\ lucky.nugroho@mercubuana.ac.id
}

\begin{abstract}
Purpose of this study is to determine economic fundamentals influence and financial performance on non-performing loans in sharia banks in Indonesia. Used quarterly panel data from 20082016, which came from BPS, BI, and OJK. Eleven banks used as a sample, with a purposive sampling approach. Using regression methods, with the dependent variable is NPF, and independent variable for economic fundamentals using exchange rates, inflation, GDP and financial performance with FDR, CAR, OER. Result shown that fundamental economice do not affect the NPF and OER as a financial performance has a positive and significant influence to $N P F, C A R$ has negative and significant influence to NPF, but has no effect to FDR.
\end{abstract}

Keywords: NPF, Exchange Rate, Inflation, GDP, FDR, CAR, OER.

\begin{abstract}
ABSTRAK
Penelitian ini bertujuan untuk mengetahui pengaruh fundamental ekonomi dan kinerja keuangan terhadap kredit bermasalah pada bank syariah di Indonesia. Data yang digunakan berupa data panel, dalam kuartalan pada 2008-2016, yang berasal dari BPS, BI, dan OJK. Sampel yang digunakan sebanyak 11 bank, dengan pendekatan pusposive sampling. Metode yang dipakai regresi, dengan variabel terikatnya berupa NPF, dan variabel bebasnya untuk fundamental ekonomi menggunakan kurs, inflasi, PDB dan kinerja keuangannya dengan FDR, CAR, BOPO. Adapun hasilnya fundamental ekonomi tidak berpengaruh terhadap NPF dan kinerja keuangan yang berupa BOPO mempunyai pengaruh yang positif dan signifikan terhadap NPF, CAR mempunyai pengaruh yang negatif dan signifikan terhadap NPF, namun FDR tidak berpengaruh.
\end{abstract}

Kata Kunci: $N P F$, Kurs, Inflasi, PDB, FDR, CAR, BOPO.

\section{PENDAHULUAN}

Perbankan merupakan institusi lembaga keuangan yang sering dijadikan motor penggerak roda perekonomian (Usman, 2018). Hal ini, juga diterapkan di Indonesia karena dengan memiliki populasi penduduk yang banyak, merupakan potensi pasar bagi perbankan (Nugroho, 2017). Namun, dalam pelaksanaan sistem perbankan agak berbeda 
EkoNiKa | Vol. 4, No. 2, September 2019 : 126-139 Pengaruh Fundamental ekonomi.. (Soekapdjo, dkk)

dengan negara lain, karena sebagai negara yang mayoritas penduduknya muslim terbesar di dunia, menerapkan dual banking system, yakni perbankan konvensional dan syariah (Soekapdjo, 2018). Perbankan sebagai lembaga intermediary, merupakan institusi yang high regulated, karena dampak kebijakanya dapat berakibat systemic risk. Pada 1997, Indonesia mengalaminya dan berimplikasi dengan ditutupnya 16 bank, bahkan di 2008 merembet ke bidang politik. Kejadian ini, merupakan effect spiral dari asymmetric information, yang merupakan sumber gejolak pengganggu dari sistem keuangan, kemudian berdampak pada sistem produksi dan penyerapan tenaga kerja, akhirnya berdampak pada krisis ekonomi, yang ditandai dengan penurunan pertumbuhan ekonomi (gambar 1).

Gambar 1. Pertumbuhan Ekonomi Indonesia, Pada 1994-2016 (Persen)

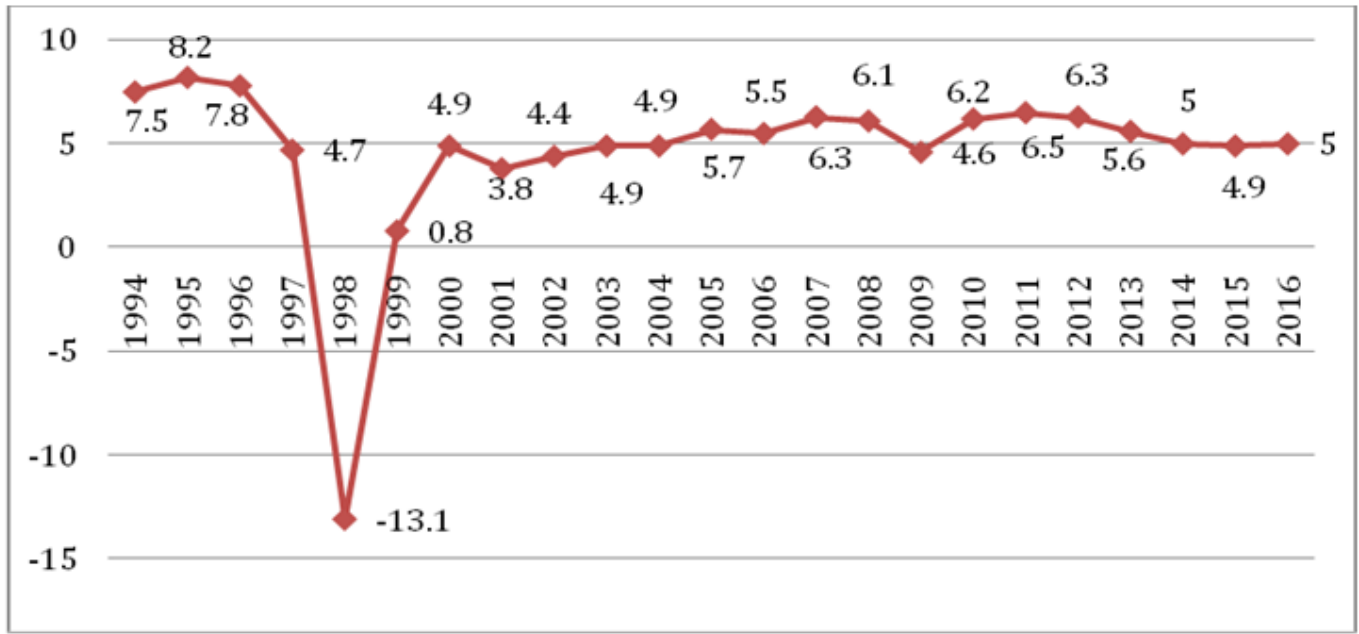

Sumber: BPS

Bank konvensional merupakan institusi yang paling terkena dampak dari systematic risk. Keadaan ini, menunjukkan bahwa bank syariah lebih sustainable. Penerapan sistem dari keduanya berbeda, yakni bunga dan bagi hasil. Prinsip bagi hasil, menganggap nasabah sebagai partnership, sehingga terjadi pembagian keuntungan dan resiko yang adil, maka kedua belah pihak akan lebih bertanggung jawab. Adapun dampaknya, terjadi pertumbuhan market share dari bank syariah (gambar 2). 
EkoNiKa | Vol. 4, No. 2, September 2019 : 126-139 Pengaruh Fundamental ekonomi.. (Soekapdjo, dkk)

Gambar 2. Market Share Bank Syariah, Pada 2008-2016 (Persen)

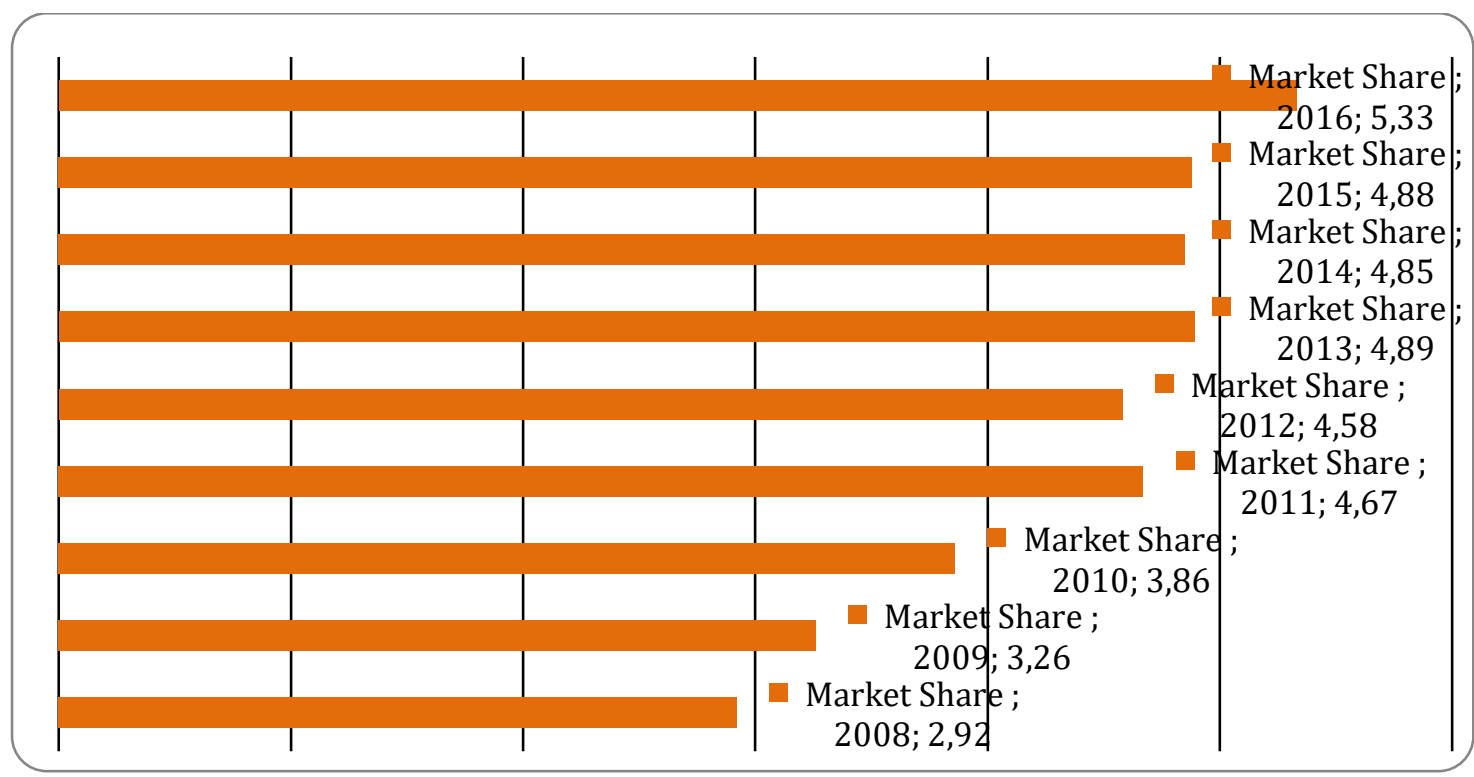

Sumber: OJK

Perkembangan bank syariah sangat kondusif, karena bersifat market driven, yang ditunjang dengan dorongan bottom up yang bertumpu pada sektor riil, serta regulatory regime yang baik (adanya kesepakatan antara Dewan Syariah Nasional (DSN), Majelis Ulama Indonesia (MUI), Institusi, dan masyarakat). Kesemuanya, tidak terlepas dari keyakinan masyarakat bahwa keberadaan bank syariah akan memberikan maslahat bagi pertumbuhan dan pemerataan ekonomi. Hal ini, tercermin dari perkembangan aset bank syariah yang memeiliki trend meningkat (gambar 3).

Gambar 3. Perkembangan Aset Bank Syariah, Pada 2008-2016 (Rp. Triliun)

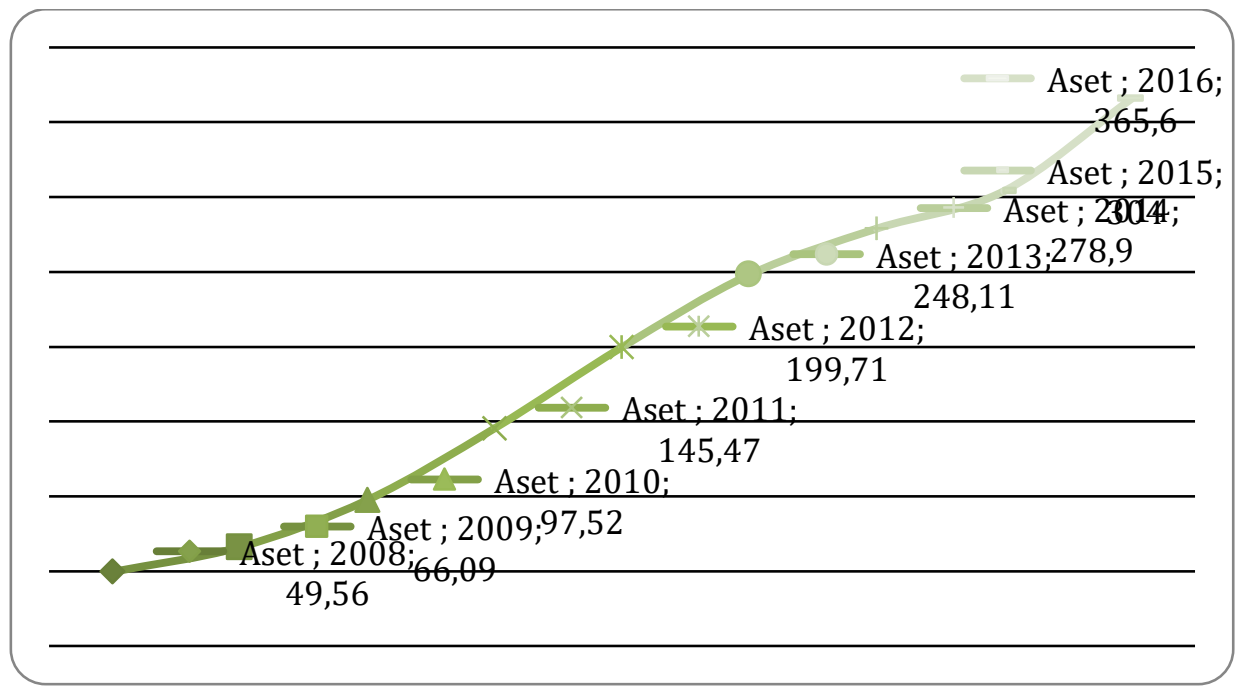

Sumber: OJK 
Indikator perbankan yang sehat, dapat terlihat dari kemampuan perbankan dalam menyalurkan kredit, berupa non perfoming loan (NPL) pada bank konvensional atau Non Performing Financing (NPF) pada bank syariah. Adanya Bad luck yang terbentuk namun pihak manajemen tidak dapat mengantisipasi faktor eksternal, akan berdampak pada terjadi kegagalan efisiensi dari perbankan, yang berakibat terjadinya krisis di sektor perbankan (Berger dan Young, 1997). Jadi, adanya kredit bermasalah dapat disebabkan oleh pengaruh dari fundamental ekonomi dan kinerja keuangannya. Maka dari itu, agar dapat mencegah terjadinya pembiayaan bermasalah, perlu mengeetahui penyebab dari pembiayaan bermasalah tersebut, sehingga perlu dilakukan penelitian pengaruh faktor fundamental ekonomi dan kinerja keuangan terhadap kredit bermasalah pada bank syariah di Indonesia.

\section{KAJIAN LITERATUR}

Jensen dan Meckling (1976), menurutnya dalam kontrak (nexus of contract) pengelolaan perusahaan, pada saat penggunaan dan pengendalian sumber daya, terdapat pemisahan antara fungsi kepemilikan (principle) dengan fungsi manajemen (agent). Pemisahan fungsi ini (Meisser, et al, 2008), akan mengakibatkan terjadinya asymetris information dan conflict of interest. Upaya untuk mengatasinya akan menimbulkan biaya keagenan (agency cost). Untuk mengurangi biaya dan meningkatkan nilai perusahaan dapat menggunakan manajemen resiko (Schoeek, 2002). Dengan demikian, menurut Kajuter dan Kumala (2005), tindakan tersebut akan mengurangi asymetris information dan menghindari perilaku oportunis dari manajer. Watts dan Zimmerman (1986), dengan positif accounting theory, mengungkapkan bahwa secara luas principle bukan hanya sebagai pemilik perusahaan, namun dapat juga pemegang saham, kreditur, dan pemerintah. Eisenhard (1989), mengungkapkan agency theory dilakukan berdasarkan asumsi Sifat manusia memiliki sifat untuk mementingkan diri sendiri (self interest) dan tidak menyukai risiko, terdapat konflik antar anggota di dalam suatu organisasi, dan adanya asymmetric information antara principle dan agent. Agar kondisinya dapat lebih kondusif, sehingga akan meningkatkan kinerja perbankan perlu menerapkan enterprise theory, karena dalam teori ini yang menjadi pusat perhatian adalah keseluruhan pihak 
EkoNiKa | Vol. 4, No. 2, September 2019 : 126-139 Pengaruh Fundamental ekonomi.. (Soekapdjo, dkk)

yang terlibat baik yang secara langsung maupun tidak langsung dengan perusahaan (Harahap, 2001).

Nilai kurs menggambarkan kestabilan ekonomi suatu negara. Penguatan nilai kurs, menandakan bahwa kondisi perekonomian baik. Jadi, Perubahan kurs akan berpengaruh pada kelancaran usaha nasabah, terutama yang menjalankan usahanya menggunakan bahan baku impor, bahkan dapat memukul usaha nasabah dan dampaknya akan meningkatkan rasio pembiayaan bermasalah. Keadaan ini, sesuai dengan penelitian Setiawan dan Bagaskara (2016), Shingjergji (2013), Farhan dkk (2012), Simon dkk (2010) yang mengungungkapkan bahwa kurs berpengaruh positif terhadap NPF.

Inflasi dapat mengakibatkan daya beli uang akan menurun, dampaknya biaya yang dikeluarkan debitur dalam usahanya akan meningkat, yang mengakibatkan kesulitan dalam pengembalian dana. Dengan demikian, inflasi yang tinggi akan memberikan dampak negatif pada kondisi sosial ekonomi masyarakat, yakni pendapatan riil menurun sehingga standar hidup masyarakat juga turun, ketidakpastian bagi pelaku ekonomi dalam mengambil keputusan, dan tingginya inflasi domestik dibandingkan negara lain, akan berdampak pada tingkat suku bunga riil menjadi tidak kompetitif. Kejadian tersebut, sesuai dengan penelitian Wulandary (2016), Poetry dan Sanrego (2011), Farhan dkk (2012), Simon dkk (2010) yang mengungungkapkan bahwa inflasi berpengaruh positif terhadap NPF.

PDB menggambarkan kondisi perekonomian suatu negara. Meningkatnya GDP, menunjukkan adanya peningkatan produktivitas, yang diikuti dengan peningkatan penjualan, dan berdampak pada peningkatan pendapatan. Kondisi ini, akan mempermudah nasabah dalam mengembalikan pinjamannya. Namun demikian, adanya ekspansi pinjaman yang besar justru akan memperbesar resiko yang akan diterima bank. Keadaan ini, sesuai dengan penelitian Wibowo dan Saputra (2017), Setiawan dan Bagaskara (2016), Ha dkk (2016), Wulandari (2016), Firmansyah (2014), Setiawan dan Putri (2013), Farhan dkk (2012), Faiz (2010), Raphael (2010) yang mengungkapkan bahwa PDB berpengaruh negatif terhadap NPF.

FDR merupakan kemampuan dari besarnya peluang yang akan muncul terhadap pembiayaan bermasalah. Artinya, semakin tinggi FDR akan semakin tinggi pula peluang resiko pembiayaan yang akan terjadi, dan sebaliknya. Hal ini, dikarenakan dengan semakin tinggi FDR, bank akan menetapkan nisbah yang akan memberikan return tinggi, 
Walaupun demikian, agar tidak terjadai permasalahan di kemudian hari, bank perlu juga membatasi pemberian pinjaman, dengan cara menjaga moral hazard. Hal ini, sesuai dengan penelitian Poetry dan Sanrego (2011) yang mengungkapkan bahwa FDR berpengaruh negatif terhadap NPF.

Modal merupakan faktor penting untuk pengembangan bisnis dan sekaligus dapat menampung resiko kerugian. CAR yang tinggi akan semakin kuat kemampuan bank untuk menanggung resiko. Hal ini, terjadi karena bank mampu membiayai operasinya, sehingga dapat memberikan kontribusi keuntungan yang besar. Akan tetapi, dalam memberikan pinjaman bank perlu berhati-hati dengan resiko yang akan diperolehnya. Dengan demikian, sesuai dengan penelitian Wibowo dan Saputra (2017), Setiawan dan Bagaskara (2016), Poetry dan Sanrego (2011), yang mengungkapkan bahwa CAR berpengaruh negatif terhadap NPF.

BOPO merupakan indikator efisiensi dan efektivitas biaya operasional dari bank. BOPO rendah berarti semakin efisien bank dalam mengendalikan biaya operasionalnya. Dengan demikian, adanya efisiensi biaya akan meningkatkan keuntungan bank, dengan resiko yang juga akan menurun. Kondisi ini, sesuai dengan penelitian Wijoyo (2016) dan Raphael (2010) yang mengungkapkan bahwa BOPO berpengaruh positif terhadap NPF.

\section{METODE PENELITIAN}

Dalam penelitian ini, menggunakan data kuartalan pada 2008-2016, berupa data panel. Data tersebut berasal dari Badan Pusat Statistik (BPS), Bank Indonesia (BI), dan Otoritas Jasa Keuangan (OJK). Sampel sebanyak 11, bank dengan pengambilan sampel menggunakan pusposive sampling. Variabel terikatnya menggunakan NPF, dan variabel bebasnya untuk fundamental ekonomi menggunakan kurs, Inflasi, PDB dan kinerja keuangannya dengan FDR, CAR, BOPO (Tabel 1).

Tabel 1. Variabel dan Pengukuran

\begin{tabular}{lcc}
\hline \multicolumn{1}{c}{ Nama Variabel } & Pengukuran & Skala \\
\hline $\begin{array}{l}\text { Non Perforrming } \\
\text { Financing (NPF) }\end{array}$ & NPF $=\frac{\text { Pembiayaan kolektif KL }+\mathrm{D}+\mathrm{M}}{\text { Total Pembiayaan }}$ & Rasio \\
$\begin{array}{l}\text { Financing Debt Ratio } \\
\text { (FDR) }\end{array}$ & FDR $=\frac{\text { Pembiayaan Bank }}{\text { Total Dana Pihak Ketiga }}$ & Rasio \\
& & Ratio
\end{tabular}




\begin{tabular}{|c|c|c|}
\hline $\begin{array}{l}\text { Capital Adequacy } \\
\text { Ratio (CAR) }\end{array}$ & $\mathrm{CAR}=\frac{\text { Modal }}{\text { Aktiva Tetap Menurut Resisko }}$ & \\
\hline $\begin{array}{l}\text { Beban Operasional } \\
\text { Terhadap Pendapatan } \\
\text { Opersaioanl (BOPO) }\end{array}$ & $\mathrm{BOPO}=\frac{\text { Beban Operasional }}{\text { Pendapatan Operasional }}$ & Ratio \\
\hline Kurs & $\begin{array}{l}\text { Perbandingan } \\
\text { nilai mata uang Rupiah terhadap USD } \\
\text { yang dinyatakan dengan Rp. per USD }\end{array}$ & Rasio \\
\hline Inflasi & $\begin{array}{l}\text { Pertumbuhan IHK dari bulan satu ke bulan yanga } \\
\text { lain yang dinyatakan dengan formulasi } \\
\qquad \text { Inflasi }=\frac{\mathrm{IHK}_{\mathrm{t}}-\mathrm{IHK}_{\mathrm{t}-1}}{\mathrm{IHK}_{\mathrm{t}-1}} \times 100 \%\end{array}$ & Rasio \\
\hline PDB & $\begin{array}{l}\text { Produk Domestik Bruro Riil dengan tahun dasar } \\
\text { tahun } 2010 \text { data kuartalan }\end{array}$ & Rasio \\
\hline
\end{tabular}

Metodenya menggunakan regresi. Adapun model yang dipakai dalam penelitian ini adalah:

$$
\mathrm{NPF}=\beta_{1}+\beta_{2} \text { Kurs }+\beta_{3} \text { Inflasi }+\beta_{4} \mathrm{PDB}+\beta_{5} \mathrm{FDR}+\beta_{6} \mathrm{CAR}+\beta_{7} \mathrm{BOPO}+\varepsilon_{\mathrm{it}}
$$

\section{Keterangan:}

$\mathrm{NPF}=$ Non Performing Financing (Persen).

Kurs = Perbandingan nilai rupiah terhadap dolar Amerika (Rp. per USD).

Inflasi = Prosentase perubahan IHK dari bulan ke bulan (Persen),

PDB = Produk Domestik Bruto Riil dengan tahun dasar 2010 (Rp milyar).

FDR = Financing Debt Ratio (Persen).

CAR = Capital Adequate Ratio (Persen).

BOPO = Rasio Beban Opersional dengan Pendapatan Operasional (Persen).

$\varepsilon \quad=$ Residual (error)

\section{PEMBAHASAN}

Maybank Syariah memiliki rata-rata NPF tertinggi dan BCA Syariah yang terendah. Namun demikian, beberapa bank syariah memiliki nilai rata-rata NPF di bawah dan di atas NPF industri perbankan syariah. BCA syariah, BNI Syariah, Bank Mega Syariah, Bank Syariah BUKOPIN, dan Panin Syariah merupakan bank yang memiliki NPF di bawah rata-ratanya dan Bank Muamalat, BSM, BRI Syariah, BJB Syariah, Bank 
Victoria Syariah, Maybank Syariah memiliki nilai NPF lebih tinggi dibandingkan dengan NPF industri perbankan syariah, yakni di atas 3,741 persen.

Bank yang memiliki FDR tertinggi adalah Maybank Syariah dan yang terendahnya Victoria Syariah. Perbankan syariah yang memiliki FDR di atas ketentuan Bank Indonesia (Maksimum FDR sebesar 110 persen) yakni Bank Panin Syariah dan Maybank Syariah. BNI syariah, bank Mega Syariah, Bank Mualamat, BSM, Bank Syariah Bukopin, BCA Syariah, BRI Syariah, BJB Syariah dan Bank Victoria Syariah memiliki nilai rata-rata FDR dibawah ketentuan Bank Indonesia.

CAR perbankan syariah memiliki nilai rata-rata sebesar 25,692 persen. Beberapa bank syariah memiliki nilai CAR lebih tinggi dari CAR industri perbankan syariah yaitu BCA syariah, Bank Victoria Syariah, Bank Panin Syariah dan Maybank Syariah. Untuk bank syariah lainnya yang memiliki rasio CAR yang lebih rendah dari CAR industri perbankan, yakni BNI Syariah, Bank Mega syariah, Bank Muamalat, BSM, Bank Syariah Bukopin, BRI Syariah dan BJB syariah.

BOPO perbankan syariah memiliki nilai rata-rata sebesar 91,473 persen. Beberapa bank syariah yang memiliki nilai BOPO lebih kecil dari BOPO industri perbankan syariah adalah BNI syariah, Bank Mega Syariah, bank Muamalat, BSM, BCA Syariah dan Bank Panin Syariah. Beberapa bank syariah yang lain memiliki rasio BOPO yang lebih besar dibandingkan BOPO industri perbankan syariah, yakni Bank Syariah Bukopin, BRI Syariah, BJB Syariah, Bank Victoria Syariah dan Maybank Syariah.

Tabel 2. Rata-Rata NPF, LDR, CAR, dan BOPO Perbankan Syariah,

Pada 2011-2016 (Persen)

\begin{tabular}{l|c|c|c|c}
\hline \multicolumn{1}{c|}{ BANK } & NPF & FDR & CAR & BOPO \\
\hline BNI Syariah & 2.61 & 88.12 & 17.924 & 85.561 \\
MEGA Syariah & 3.63 & 92.83 & 16.087 & 89.496 \\
MUAMALAT & 3.92 & 92.59 & 13.564 & 89.98 \\
BSM & 4.56 & 86.92 & 13.684 & 84.466 \\
BUKOPIN Syariah & 3.39 & 93.07 & 14.117 & 93.126 \\
BCA Syariah & 0.32 & 87.76 & 36.558 & 90.995 \\
BRI Syariah & 3.91 & 94.69 & 14.728 & 93.185 \\
BJB Syariah & 5.74 & 98.73 & 21.975 & 95.412 \\
VICTORIA Syariah & 5.14 & 83.88 & 36.135 & 103.95 \\
PANIN Syariah & 1.15 & 114.31 & 34.24 & 81.861 \\
Maybank Syariah & 6.78 & 187.37 & 64.234 & 98.172 \\
Perbankan Syariah & 3.74 & 101.84 & 25.692 & 91.473 \\
\hline
\end{tabular}

Sumber: BI,

OJK. BSM 
Kondisi ekonomi makro pada 2011.1-2016.4 di Indonesia mengalami trend yang menurun untuk kurs rupiah terhadap USD, tetapi meningkat pada PDB dan Inflasi. Nilai rata-rata kurs sebesar Rp 10.930 per USD, dengan nilai kurs tertinggi sebesar Rp 8.653 per USD yang terjadi pada 2011.4, sedangkan terendahnya sebesar Rp 13.778 per USD pada 2016.1. Rata-rata inflasinya sebesar 0,219 persen, yang artinya selama periode tersebut, rata-rata kenaikan nilai perkuartalnya sebesar 0,219 persen, dengan inflasi tertinggi pada 2014.1 sebesar 1,070 persen, namun terendahnya terjadi pada 2016.4 sebesar minus 0,450 persen. PDB memiliki nilai rata-rata sebesar Rp 2.026 .780 milyar, dengan nilai tertingginya sebesar Rp 2.354 .798 milyar yang terjadi pada 2016, dan terendahnya sebesar Rp 1.748.731 milyar pada 2011.

Pemilihan model dilakukan dengan menggunakan chow test dan Hauseman test, dan dilanjutkan dengan uji Breusch-Pagan. Hasil pengujian chow test ditunjukkan dengan nilai probabilitas dari cross section chisquare sebesar $0,000<0,05$, yang artinya model yang terpilih adalah fixed effect. Untuk Hausman test diperoleh nilai probabilitas $1,000>0.05$, sehingga model yang dipilih adalah random. Hasil pengolahan data untuk pengujian LM, yang menggunakan Breusch-Pagan, diperoleh nilai probabilitas Breaush Pagar sebesar $0.0000<0.05$, denan demikian model yang paling baik untuk dipilih adalah random effect.

Hasil pengolahan untuk model fit ditunjukkan dengan nilai koefisien determinasi sebesar 0,470799, yang artinya variasi atau perilaku dari variabel independen yaitu kurs, inflasi, PDB, FDR, CAR, dan BOPO mampu menjelaskan variasi atau perilaku dari variabel dependen yaitu NPF sebesar 47,07 persen, sedangkan sisanya yang 53,93 persen adalah variasi dari variabel independen lain yang mempengaruhi NPF, tetapi tidak dimasukkan dalam model. Hasil temuan ini menunjukkan bahwa model NPF menghasilkan model fit yang baik untuk menganalisis perilaku NPF dari perusahaan perbankan syariah.

Pengujian parsial digunakan untuk menguji pengaruh dari masing-masing variabel independen untuk faundamental ekonominya yang menggunakan kurs, inflasi, PDB, dan konerja keuanganya menggunakan FDR, CAR, BOPO terhadap variabel dependennya yaitu NPF. Adapun hasil penelitiannya pada Tabel 3: 
Tabel 3. Pengujian Hipotesis Model Penelitian

\begin{tabular}{l|c|c|c|l}
\hline \multicolumn{1}{c|}{ Deskripsi } & Estimate & C.R. & $\mathrm{P}$ & \multicolumn{1}{|c}{ Kesimpulan } \\
\hline $\begin{array}{l}\text { Kurs berpengaruh positif } \\
\text { terhadap NPF }\end{array}$ & 0.0002 & 1.128 & 0.2600 & $\begin{array}{l}\text { Hipotsis tidak } \\
\text { didukung }\end{array}$ \\
\hline $\begin{array}{l}\text { Inflasi berpengaruh positif } \\
\text { terhadap NPF }\end{array}$ & 0.1379 & 0.396 & 0.6919 & $\begin{array}{l}\text { Hipotsis tidak } \\
\text { didukung }\end{array}$ \\
\hline $\begin{array}{l}\text { PDB berpengaruh negatif } \\
\text { terhadap NPF }\end{array}$ & $6.72 \mathrm{E}-07$ & 0.2683 & 0.7887 & $\begin{array}{l}\text { Hipotsis tidak } \\
\text { didukung }\end{array}$ \\
\hline $\begin{array}{l}\text { FDR berpengaruh negatif } \\
\text { terhadap NPF }\end{array}$ & 0.0124 & 1.598 & 0.1112 & $\begin{array}{l}\text { Hipotesis tidak } \\
\text { didukung }\end{array}$ \\
\hline $\begin{array}{l}\text { CAR berpengaruh negatif } \\
\text { terhadap NPF }\end{array}$ & -0.0195 & -2.200 & 0.0287 & $\begin{array}{l}\text { Hipotsis } \\
\text { didukung }\end{array}$ \\
\hline $\begin{array}{l}\text { BOPO berpengaruh positif } \\
\text { terhadap NPF }\end{array}$ & 0.1008 & 3.733 & 0.0002 & $\begin{array}{l}\text { Hipotesis } \\
\text { didukung }\end{array}$ \\
\hline
\end{tabular}

Sumber : data diolah

Pengaruh kurs terhadap NPF menghasilkan nilai koefisien estimasi sebesar 0,0002, yang artinya naiknya kurs rupiah terhadap USD (depresiasi) akan meningkatkan NPF dan sebaliknya, turunnya kurs rupiah terhadap dolar (apresiasi) akan menurunkan NPF. Dengan nilai p-value sebesar 0,2600>0,05, yang artinya kurs tidak berpengaruh terhadap NPF. Keadaan ini sesuai dengan penelitian Ha (2016), Vatansever dan Hapsen (2015), Achmad dan Bashir (2013).

Untuk pengujian pengaruh dari inflasi terhadap NPF ditunjukkan dengan nilai koefisien sebesar 0,1379, yang artinya meningkatnya inflasi akan meningkat NPF dan sebaliknya, menurunnya inflasi akan menurunkan NPF. Dengan nilai p-value sebesar 0,6919>0,05, yang artinya inflasi tidak berpengaruh terhadap NPF. Penelitian ini sesuai dengan Ha (2016), Havids dan Setiawan (2015), Asnaini (2014).

Hasil pengolahan untuk pengaruh dari PDB terhadap NPF ditunjukkan dengan nilai koefisien estimasi 6,72E-06, yang artinya meningktnya PDB akan meningkatkan NPF dan sebaliknya, menurunnya PDB akan menurunkan NPF. Dengan nilai p-value sebesar 0,7887<0,05, yang artinya PDB tidak berpengaruh terhadap NPF. Hal ini sesuai dengan penelitian Vetansever dan Hapsen (2015), Waemustafa dan Sukri (2015), Asnaini (2014).

Hasil pengolahan untuk pengujian pengaruh dari FDR terhadap NPF ditunjukkan dengan nilai koefisien estimasi sebesar 0,0124, yang artinya meningkatnya FDR akan 
meningkatkan NPF dan sebaliknya, menurunnya FDR akan menurunkan NFP. Dengan nilai p-value sebesar $0,1112<0,05$, yang artinya FDR tidak berpengaruh terhadap NPF. Hal ini sesuai dengan hasil penelitian Asnaini (2014), Havids dan Setiawan (2015), Setiawan dan Bagaskara (2016) bahwa FDR tidak berpengaruh terhadap NPF.

Variabel CAR ditunjukkan dengan nilai koefisien estimasi sebesar minus 0,0195, yang artinya meningkatkan CAR akan menurunkan NPF dan sebaliknya, menurunnya CAR akan menaikkan NPL. Dengan nilai p-value sebesar $0,0287<0,05$, yang artinya terbukti bahwa terdapat pengaruh yang negatif dan signifikan antara CAR dengan NPL terbukti. Penelitian ini sesuai dengan Asnaini (2014), Wibowo dan Saputra (2017), Setiawan dan Bagaskara (2016), Poetry dan Sanrego (2011).

Untuk pengujian pengaruh dari BOPO terhadap NPF diperoleh koefisien estimasi sebesar 0,1008, yang artinya meningkatnya BOPO akan meningkatkan NPF dan sebaliknya, menurunnya BOPO akan menurunkan NPF. Dengan nilai p-value sebesar $0,0002<0,05$, yang artinya terbukti bahwa terdapat pengaruh yang positif dan signifikan antara BOPO dengan NPF terbukti signifikan. Hasil penelitian ini sesuai dengan Wijoyo (2016), Raphael (2010).

\section{SIMPULAN}

Fundamental ekonomi (kurs, inflasi, PDB) dan kinerja keuangan (FDR, CAR, BOPO) dapat menjelaskan terhadap NPF sebesar 47,0799 persen. Fundamental ekonomi tidak berpengaruh terhadap NPF dan kinerja keuangan yang berupa BOPO mempunyai pengaruh yang positif dan signifikan terhadap NPF, CAR mempunyai pengaruh yang negatif dan signifikan terhadap NPF, namun FDR tidak berpengaruh. Agar Bank Syariah dapat tetap dalam kondisi sehat, perlu menjaga kinerja keuangan dengan meningkatkan sumber daya manusia beserta faktor pendukungnya baik yang internal maupun eksternal, sehingga dapat mengantisipasi dampak dari gejolak ekonomi makro, yang dapat mengakibatkan systematic risk.

\section{DAFTAR PUSTAKA}

Asnaini, Sri Wahyuni, (2014), Faktor-Faktor yang Mempengaruhi Non Performing Financing (NPF) Pada Bank Umum Syariah di Indonesia, Jurnal TEKUN, Vol. $5(2)$. 
Ahmad, Fawad and Taqadus Bashir. (2013). Explanatory Power of Bank Specific Variables as Determinants of Non-Performing Loans: Evidence form Pakistan Banking Sector. World Applied Sciences Journal. Vol 22(9).

Berger, A.N., De Young R. (1997). Problem loans and cost efficiency in commercial banking. Journal of Banking and Finance. Vol. 21(6)..

Eisenhardt. (1989). Agency Theory: An Assessment and Review. The Academy of Management Review. Vol. 14(1).

Firmansyah, I. (2015). Determinant of Performing Loan: The Case of Islamic Bank in Indonesia. Buletin Ekonomi Moneter dan Perbankan. Vol. 17(2).

Farhan, M., A. Sattar, A. H. Chaudhry \& F. Khalil. (2012). Economic Determinants of Non Performing Loans: Perception of Pakistani Bankers. European Journal of Business and Management. Vol. 4(19).

Faiz, Ihda A. (2010). Ketahanan Kredit Perbankan Syariah Terhadap Krisis Keuangan Global. Jurnal Ekonomi Islam: La_Riba,.Vol. 4(2).

Havidz, Shinta Amalina Hazrati dan Chandra Setiawan. (2015). Bank Efficiency and Non-Performing Finance (NPF) in The Indonesian Islamic Banks. Asian Journal of Economic Modelling. Vol. 3(3).

Ha, Vo Thi Ngoc., Le Vinh Trien and Ho Diep. (2014). Macro Determinants on Non Performing Loans and Strees of Vietnamese Commercial Banks Credit Risk. VNU Journal of Science: Economics and Business. Vol. 30(5E).

Kajuter, P. and H.I. Kumala. (2005). Open Book Accounting in Networks: Potential Achievements and Reason for Failures. Management Acounting Reseach. Vol. $16(2)$.

Harahap, Sofyan Syafri. (2001). Menuju Perumusan Teori Akuntansi Islam. Jakarta: PT. Pustaka Quantum.

Messier, W.F., Glover, S.M. dan Prawitt, D.F. (2008). Auditing \& Assurance Services A Systematic Approach.New York: McGraw-Hill Irwin.

Nugroho, Lucky., Wiwik Utami, Caturida Meiwanto Doktorlina, Soeharjoto Soekapdjo, Tengku Chandra Husnad. (2017). Islamic banking capital challenges to increase business expansion (Indonesia cases). International Journal of Commerce and Finance. Vol.3(2). 
Ouhibi, S. and S. Hammami. (2015). Determinants of Non Performing Loan in The Southern Mediterranean Countries. International Journal of Accounting and Economics Studies. Vol. 3(1).

Jensen, Michael C. and William H. Meckling. (1976). Theory of the firm: Managerial behavior, agency costs and ownership structure. Journal of Financial Economics. Vol. 3(4).

Poetry, Zakiyah Dwi dan Yulizar D. Sanrego . (2011). Pengaruh Variabel Makro dan Mikro Terhadap NPL Perbankan Konvensional dan NPF Perbankan Syariah. TAZKIA Islamic Finance \& Business Riview. Vol. 6(2).

Raphael, Pinoza and Ananthakrisna, Prazad. (2010). Non Performing Loans GCC Banking System and Their Macroeconomics Effect. IMF Working Paper. WP/10/224.

Soekapdjo, Soeharjoto., Lucky Nugroho, Ahmad Badawi, Wiwik Utami. (2018). Bad debt issues in Islamic bank: macro and micro influencing (Indonesia cases). International Journal of Commerce and Finance. Vol. 4(1).

Setiawan dan Bagaskara. (2016). Non-Performing Financing (NPF) and Cost Efficiency of Islamic Banks in Indonesia Period 2012Q1 to 2015Q2. Journal of Emerging Issues in Economics, Finance and Banking. Vol. 5 (1).

Setiawan, Chandra and Monita Eggy Putri. (2013). Non-Performing Financing and Bank Efficiency of Islamic Bank in Indonesia. Journal of Islamic Finance and Business Research.Vol. 2(1).

Shingjergjii, Ali. (2013). Impact of Bank Specific Variables on The Non Performing Loans Ratio in Albanian Banking System. Journal of Finance and Accounting. Vol. 4(1).

Simon, Arif Budiman. (2010). Analisis Dampak Terjadinya Shock Variabel Moneter Terhadap Non Performing Loan Ratio di Indonesia. Kajian Stabilitas Keuangan Bank Indonesia. No. 14.

Schoeck, Gerhard. (2002). Risk Management and Value Creation in Financial Institution. Willey. USA.

Usman, Bahtiar., Syofriza Syofyan, Lucky Nugroho, Soeharjoto. (2018). Foreign Bank Penetration And Its Impact On Banking Industries. Eurasian Journal of Economics and Finance. Vol. 6(1). 
Vatansever, M. and A. Hapsen . (2015). Determining Impact on Non-Performing Loan Ratio in Turkey. Journal of Applaid Finance and Banking. Vol. 5(1).

Wibowo, Sigit Arie dan Wahyu Saputra. (2017). Pengaruh Variabel Makro dan Mikro Ekonomi Terhadap Pembiayaan Bermasalah Pada Bank Syariah. Jurnal Ilmiah Akuntansi. Vol. 2(1).

Wulandari. (2016). Analisis Pengaruh Pertumbuhan Ekonomi, Inflasi, Ekspor dan Jumlah Uang Beredar Terhadap Resiko Kredit di Wilayah Asia Tenggara (ASEAN) (Studi Pada Negara Thailand, Filipina, Malaysia dan Indonesia Periode 19882014). Jurnal Ilmiah Mahasiswa. Vol. 4(2).

Wijoyo, Satrio. (2016). Analisis Faktor Makro Ekonomi dan Kondisi Spesifik Bank Syariah Terhadap Non Performing Finance. Jurnal Pendidikan dan Ekonomi. Vol. $5(6)$.

Waemustafa, Waeibrorheem and Suriani Sukri. (2015). Bank Specific and Macroeconomics Dynamic Determinants of Credit Risk in Islamic and Conventional Banks. International Journal of Economics and Financial Issues.Vol. 5(2).

Watts, Ross L. and Jeroid L. Zimmerman. (1986). Positive Accounting Theory. PrenticeHall Inc.

$\underline{\text { www.bi.go.id }}$

www.bps.go.id

www.ojk.go.id 